\title{
Green Synthesis of Silver Nanoparticles Using Raw Fruit Extract of Mimusops elengi and their Antimicrobial Study
}

\author{
Susanta Kumar Biswal ${ }^{1, *}$, Manoranjan Behera ${ }^{2, *}$, , Ardhendu Sekhar Rout ${ }^{1}$, Arpita Tripathy ${ }^{1}$ \\ Department of Chemistry, Centurion University of Technology and Management, Odisha, India \\ 2 Department of Basic Sciences \& Humanities, Silicon Institute of Technology, Bhubaneswar, Odisha, India \\ * Correspondence: manoranjan@ silicon.ac.in;
}

Scopus Author ID 57204049277

Scopus Author ID 7004588847

Received: 2.09.2020; Revised: 23.09.2020; Accepted: 24.09.2020; Published: 26.09.2020

\begin{abstract}
These days, nanoparticles are being considered as nano-antibiotics because of their execution of antimicrobial activities towards a broad range of microbes. Nanoparticles are used in industrial products, health, food, space, and cosmetics; thus, researchers need for a green, ecofriendly, and lowcost approach to synthesize it. Green synthesis is such an approach of synthesizing NPs using microorganisms and plants, which is free of additional impurities. We used Mimusops elengi Linn. raw fruit extract in water to reduce the silver nitrate salt to produce silver NPs. The samples were characterized using various instrumental techniques. Broadband known as Surface Plasmon Resonance found near $450 \mathrm{~nm}$ in the absorption spectrum shows the formation of Ag NPs. NPs with average hydrodynamic diameters in the ranges 20-300 $\mathrm{nm}$ were detected from DLS study having negative zeta potential value (varies between - 25.8 to $-15.8 \mathrm{mV}$ ), which suggests that as NPs surface is charged, it provides colloidal stability to the NPs in a liquid medium. FTIR study reveals that an increase in the intensity of some of the vibrational band with NP-content is due to the adsorption of some molecules on the surface of NPs. XRD pattern shows that NPs have an fcc structure. Samples were tested to have capabilities to kill both bacteria and fungi.
\end{abstract}

Keywords: nanoparticles; green synthesis; antimicrobial study; surface plasmon resonance band.

(C) 2020 by the authors. This article is an open-access article distributed under the terms and conditions of the Creative Commons Attribution (CC BY) license (https://creativecommons.org/licenses/by/4.0/).

\section{Introduction}

Noble metal nanoparticles (NPs) like silver $(\mathrm{Ag})$, gold $(\mathrm{Au})$, platinum $(\mathrm{Pt})$, palladium $(\mathrm{Pd})$, etc. synthesis is a quite difficult task. Various factors like are $\mathrm{pH}$, the concentration of precursor salt solution, temperature, the concentration of capping agent, sonication conditions, etc. affect the particle size, chemical composition, crystallinity, and shape. Variation in their size, shape, or both varies the color of the nanoparticles. Basically, there are two basic routes employed in the preparation of NPs. One such route is Top-down, wherein NPs are obtained by mechanical crushing of source material, which includes high energy ball milling, laser ablation, electro-explosion, chemical etching, etc. In the second method (i.e., bottom-up approach), the structures are built up by chemical processes where NPs are obtained as a result of an atom by atom or molecule by molecule addition. Various types of processes under this are sol-gel process, green synthesis, chemical reduction method, hydrothermal route, chemical vapors deposition (CVD), combustion, aerosol process, plasma spraying process, etc. [1-3]. Out of all the synthesis routes mentioned above, green synthesis is preferred the most as in the rest of other methods, various chemicals are used that are toxic in nature. In order to do the 
green synthesis, more eco-friendly plant-mediated nanoparticle synthesis is the best choice, as this avoids the use of toxic, carcinogenic, harsh, and expensive chemicals [2-6]. Also, various phytohormones present in the plant extracts act as good stabilizing, thus providing stability to the nanoparticles, and there is no requirement of extra capping agents or reducing agents. Out of all the metal NPs, noble metal NPs are being synthesized in a wide range because of their vast uses like catalysis, sensing, bio-medical, etc. [3-7].

Many works have been done in the field of synthesis of various noble metals nanoparticles from plant extracts. Khalil et al. [5] has synthesized silver NPs from olive leaf extract and has studied their antimicrobial properties. Various instruments like UV-Visible spectrophotometer, Fourier Transform Infrared (FTIR) spectrophotometer, Scanning Electron Microscope (SEM), etc. are used by them to study the prepared NPs. Husseiny et al. [6] has reported biosynthesis of size-controlled Ag NPs from Fusarium oxysporum. The synthesized Ag NPs show excellent antibacterial activity against pathogenic bacterias (both gram-positive and gram-negative). Their test results were found to exhibits tremendous antitumor activity against a human breast carcinoma cell line called MCF-7.

In a report, Nakkala et al. [7] evaluated antioxidant, antibacterial as well as anticancer effects of Ag NPs, which were developed using an aqueous rhizome extract of Acorus calamus. They confirmed the formation of Ag NPs using a UV-Visible spectrophotometer. Dynamic Light Scattering (DLS) study revealed the formation of $\sim 32 \mathrm{~nm}$ NPs. Aqueous flower extract of Mimusops elengi, Linn was used in the synthesis of Ag NPs, and NPs were characterized using UV-Visible \& FTIR spectrophotometer and SEM. They have reported potential antibacterial activity against both gram-positive like Staphylococcus aureus and a gramnegative E. coli bacteria [8]. Kiran Kumar et al. [9] have synthesized Ag NPs using the Mimusops elengi seed extract and characterized the sample using UV-Visible spectroscopy, FTIR spectroscopy, and TEM. The synthesized Ag NPs were found to be sensitive against both Staphylococcus aureus (S. aureus) and Escherichia coli (E. coli). These NPs also acted as an antioxidant agent against ascorbic acid. In a recent article, Farjadian et al. [10] have reported that Ag-NPs capped with metronidazole ionic liquids can be used in wound dressing applicationsExtracts of Capparis zeylanica leaves were used to develop Ag-NPs and studied their antimicrobial and antiproliferative potency. The developed Ag-NPs were reported to exhibit excellent antiproliferative activity against not only against pathogenic microbes but also on A549 cancer cell lines [11]. Renuka et al. [12] have synthesized Ag-NPs using phyllanthus emblica fruit extract and tested their medicinal efficacy. They have reported that their synthesized Ag-NPs were exhibiting significant antibacterial effects.

Aerial parts of Allium rotundum 1, Falcaria vulgaris Bernh, and Ferulago angulate Boiss extracts were used in the green synthesis of Ag-NPs and studied their antimicrobial effects. The obtained bio-synthesized Ag-NPs were reported to exhibit a good antibacterial effect on bacteria like P. aeruginosa and S. aureus [13]. Sherin et al. [14] have synthesized Ag-NPs using novel Terminalia bellerica kernel extract and studied their photocatalytic activity towards various chemicals and dyes. The synthesized Ag-NPs have exhibited a good catalytic reduction of various well known organic pollutants such as 4-nitrophenol and widely used organic dyes like methylene blue and methyl orange. Khan et al. [15] have demonstrated that Ag-NPs synthesized using the bacterial strain Bacillus sp. MB353 (PRJNA357966) exhibits good antibacterial activity against both Gram-positive and Gram-negative bacteria. 


\section{Materials and Methods}

\subsection{General procedure for preparation of Mimusops elengi, L. fruit extract in water.}

Raw fruits were collected from the Bokul tree (Mimusops elengi, L.) present on the campus of Silicon Institute of Technology, Bhubaneswar, Odisha. Then, raw fruits weighing $8.1 \mathrm{~g}$ was taken in a beaker containing $100 \mathrm{~mL}$ of deionized water (i.e., $81 \mathrm{mg} / \mathrm{L}$ ) and placed in a hot magnetic stirrer plate maintained at $100{ }^{\circ} \mathrm{C}$ for $1.5 \mathrm{~h}$. During the heating process, the beaker was covered with a watch glass to avoid loss of water. The aqueous extract was filtered using Whatman 42 paper $(2.5 \mu \mathrm{m})$ and stored in a refrigerator maintained at $\sim 10^{\circ} \mathrm{C}$. The extract is colorless to the naked eye.

\subsection{Preparation of silver salt solution in water.}

Silver salt $\left(\mathrm{AgNO}_{3}\right)$ of $99 \% \mathrm{Ag}$ was purchased from Loba Chemie to prepare Ag NPs. The salt was dissolved in a calculated amount of deionized water to form a solution of strength $32 \mathrm{mM}$. The salt solution, as such, is colorless.

\subsection{General procedure for the synthesis of Ag NPs in the aqueous plant extract.}

Freshly prepared extract solution and silver salt solution were used to synthesize stable Ag nano-colloids or nanofluids in water. At first, $5 \mathrm{~mL}$ of aqueous extract was taken in a beaker and placed in a hot magnetic stirrer maintained at $70{ }^{\circ} \mathrm{C}$. Then, the silver nitrate solution was added drop-wise using a micropipette into it under stirring condition. We prepared five samples by adding $0.05 \mathrm{~mL}, 0.1 \mathrm{~mL}, 0.15 \mathrm{~mL}, 0.2 \mathrm{~mL}$, and $0.25 \mathrm{~mL}$ of silver salt solution of strength $32 \mathrm{mM}$ to a fixed volume of extract solution $(5 \mathrm{~mL})$ of strength $81 \mathrm{mg} / \mathrm{L}$. After 1 minute of hot stirring, we observed that the color of the solution has changed to grey. It happens due to the formation of $\mathrm{Ag}$ NPs. In this investigation, the Ag-contents were varied as $0.6 \mathrm{mM}, 0.7 \mathrm{mM}$, $0.8 \mathrm{mM}, 0.90 \mathrm{mM}$, and $1.0 \mathrm{mM}$ in the presence of a fixed volume $(5 \mathrm{~mL})$ of raw fruit extract in water. As far as our knowledge and literature studies are concerned. This is a first report on the synthesis of Ag NPs with the help of raw fruits extract of the Bokul tree (Mimusops elengi, L.) in an aqueous medium.

\subsection{Measurement and analyses.}

Liquid samples in water were used to collect absorption spectra in the 200-900 nm regions. Perkin-Elmer Lambda 750 spectrophotometer was used in collecting absorbance data against wavelength. We used Perkin-Elmer FTIR Spectrometer (Spectrum 65) for collecting the FTIR data in the wavenumber regions $400-4000 \mathrm{~cm}^{-1}$ for all the samples. As it was a liquid sample, we have opted for an attenuated total reflectance mode using a ZnSe crystal as a sample holder for collecting data. Malvern Nano Zetasizer Nano Z potential analyzer was used to find the zeta-potential values and hydrodynamic diameters of all the liquid samples. This device utilizes a micro-electrophoresis technology in analyzing the liquid samples. Wide angled. Xray diffractometer (make-PHILIPS; model-PW-1710) was used to collect patterns of various samples. We prepare the sample for the diffractometer as follows: At first, liquid samples were cast on the surface of a silicon substrate. After drying it in a desiccator, it was placed in the instrument to get diffraction patterns. A monochromatic $\mathrm{CuK}_{\alpha-}$-radiation of wavelength $\lambda=$ $0.15405 \mathrm{~nm}$ was used in getting the pattern. Oxford model Leo1550 VP SEM was used to take 
the images. While taking the images, the accelerated voltage was fixed in the $2-10 \mathrm{kV}$ range. We have adopted a Disk-diffusion method in studying our samples sensitive towards microbes.

\section{Results and Discussion}

\subsection{UV-Vis and FTIR analysis.}

We studied the UV-Vis optical absorption spectra in the $230-650 \mathrm{~nm}$ regions to verify the formation and stability of NPs in an aqueous medium. The UV-Vis spectra of six number of samples consisting of consisting of (a) 0.0, (b) 0.6, (c) 0.7 , (d) 0.8 , (e) 0.9 , and (f) $1.0 \mathrm{mM}$ $\mathrm{Ag}$ NPs in an aqueous raw fruit extract of Mimusops elengi. were shown in Figure 1A. The color change from colorless to grey during the synthesis is due to the formation of NPs, and it is a result of the Surface Plasmon Resonance (SPR) phenomenon [16]. We observed two absorption bands in the spectra. One weak band at $255 \mathrm{~nm}$ is from the extract due to $\mathrm{n} \rightarrow \pi^{*}$ transition of phytochemicals present in the extract and another broadband ascribed to SPR band developed near $455 \mathrm{~nm}$ for in all the samples except sample-a (i.e., for extract). For aqueous extract, no SPR band is observed as there is no NPs in it. The SPR band near $455 \mathrm{~nm}$ suggests the formation of nearly spherical NPs $[10,11]$. Jyoti et al. [16] have reported the SPR band at 414 for Ag NPs. They have synthesized these NPs using aqueous leaves extract of Urtica dioica (Linn.). From Figure 1A, we observed that the intensity of the SPR band is increasing with increasing the Ag-content due to the presence of a large number of Ag-NPs. Also, the SPR band (Figure 1B.) is shifting to a higher wavelength side with increasing in Ag-content. It is due to an increase in the cluster size of NPs [13-18]. The band near $255 \mathrm{~nm}$ is shifting to a lower wavelength with Ag-content. It is a good sign as such a characteristic is required for absorbing harmful UV-light. So it suggests that our sample could act as UV-absorber or as UVprotective coating. It is reported that the SPR peak located between 410 and $450 \mathrm{~nm}$ has been attributed to the development of spherical Ag NPs 17,18].
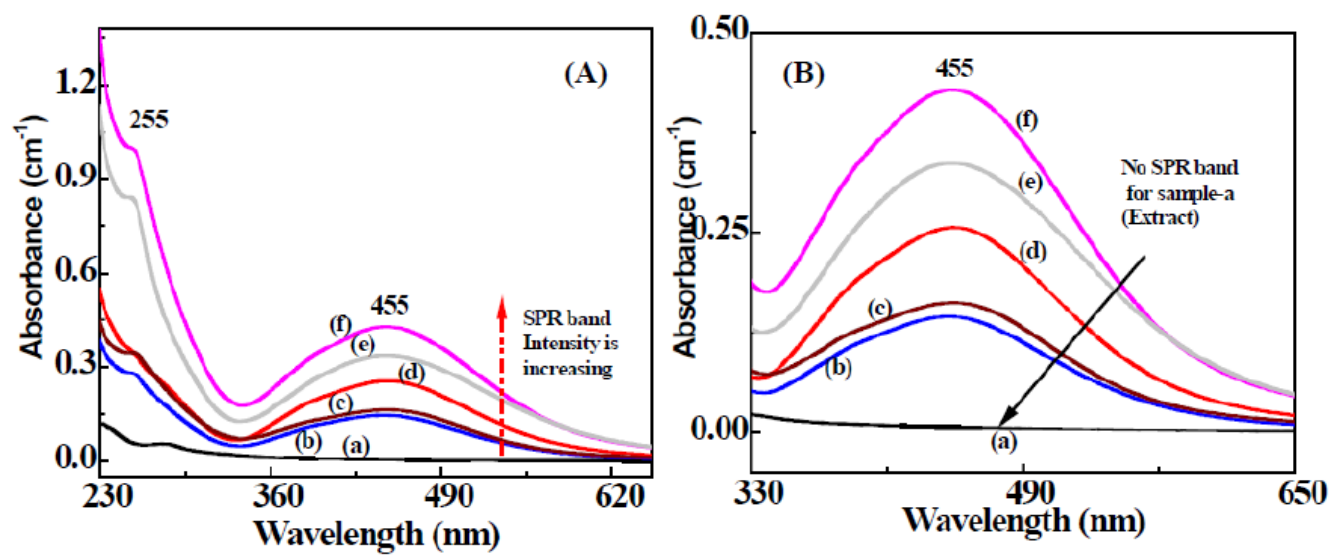

Figure 1. (A) The UV-Vis spectra of Ag-nanofluids and (B) SPR band of samples: (a) 0.0, (b) 0.6, (c) 0.7, (d) 0.8 , (e) 0.9 , and (f) $1.0 \mathrm{mM} \mathrm{Ag} \mathrm{NPs} \mathrm{in} \mathrm{an} \mathrm{aqueous} \mathrm{raw} \mathrm{fruit} \mathrm{extract} \mathrm{of} \mathrm{Mimusops} \mathrm{elengi.}$

Interfacial interaction between Ag NPs and phytochemicals like lupeol present in the plant extract was studied using FTIR spectra. FTIR study also helps in identifying the role of phytochemicals as capping and stabilizing. The FTIR spectra of six liquid samples consisting of (a) 0.0, (b) 0.6, (c) 0.7, (d) 0.8, (e) 0.9, and (f) $1.0 \mathrm{mM} \mathrm{Ag} \mathrm{NPs} \mathrm{in} \mathrm{an} \mathrm{aqueous} \mathrm{raw} \mathrm{fruit}$ extract of Mimusops elengi. were shown in Figure 2. The various FTIR bands of plant extract was found at $3350 \mathrm{~cm}^{-1}, 2925 \mathrm{~cm}^{-1}, 1635 \mathrm{~cm}^{-1}, 1335 \mathrm{~cm}^{-1}, 1045 \mathrm{~cm}^{-1}$, and $623 \mathrm{~cm}^{-1}$. In the presence of Ag NPs, it is observed from the spectra that the intensity of some selective band 
has increased, and also some band shifts either towards longer wavelength or shorter wavelength from their original position. From the spectra, it is found that there is an increase in band intensity and also shifting of some selective band. It suggests that there is some sort of interaction that occurs between Ag NPs and active sites of phytochemicals [16,18]. The band at $3350 \mathrm{~cm}^{-1}$ is due to $\mathrm{O}-\mathrm{H}$ stretching. Its intensity has increased upon the addition of more and more Ag NPs. The other bands at $2925 \mathrm{~cm}^{-1}, 1635 \mathrm{~cm}^{-1}$, and $1045 \mathrm{~cm}^{-1}$ are ascribed to aldehydic C-H stretching, amide-I, -C-O-C- stretching vibration, respectively.The various FTIR bands of plant extract was found at $3350 \mathrm{~cm}^{-1}, 2925 \mathrm{~cm}^{-1}, 1635 \mathrm{~cm}^{-1}, 1335 \mathrm{~cm}^{-1}, 1045$ $\mathrm{cm}^{-1}$, and $623 \mathrm{~cm}^{-1}$. In the presence of Ag NPs, it is observed from the spectra that the intensity of some selective band has increased, and also some band shifts either towards longer wavelength or shorter wavelength from their original position. The band at $3350 \mathrm{~cm}^{-1}$ is due to $\mathrm{O}-\mathrm{H}$ stretching. Its intensity has increased upon the addition of more and more Ag NPs. The other bands at $2925 \mathrm{~cm}^{-1}, 1635 \mathrm{~cm}^{-1}$, and $1045 \mathrm{~cm}^{-1}$ are ascribed to aldehydic $\mathrm{C}-\mathrm{H}$ stretching, amide-I, -C-O-C- stretching vibration, respectively [19].

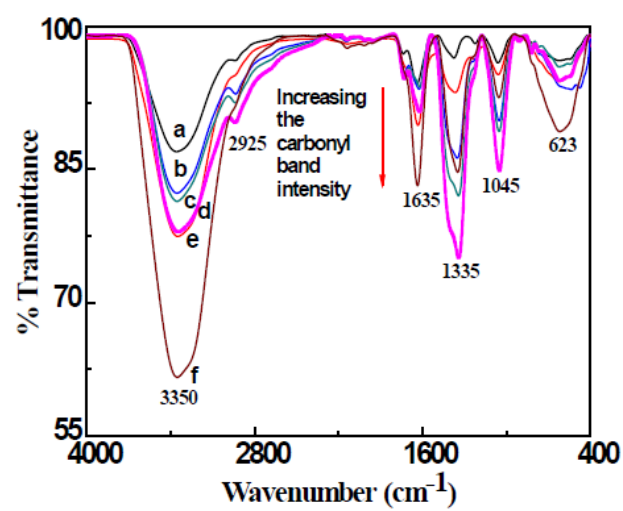

Figure 2. The FTIR spectra of liquid samples: (a) 0.0, (b) 0.6, (c) 0.7, (d) 0.8, (e) 0.9, and (f) $1.0 \mathrm{mM}$ Ag NPs in an aqueous raw fruit extract of Mimusops elengi.

\subsection{Hydrodynamic diameter and zeta-potential analysis.}

The particle size distribution of different Ag nanofluids consisting of (a) 0.6, (b) 0.7, (c) 0.8 , (d) 0.9 , and (e) $1.0 \mathrm{mM} \mathrm{Ag} \mathrm{NPs} \mathrm{in} \mathrm{an} \mathrm{aqueous} \mathrm{raw} \mathrm{fruit} \mathrm{extract} \mathrm{of} \mathrm{Mimusops} \mathrm{elengi.}$ were shown in Figure 3A. It is found from the DLS spectra that the average hydrodynamic diameter for sample-a is $230 \mathrm{~nm}$ whereas it has increased up to $340 \mathrm{~nm}$ in the sample-e.
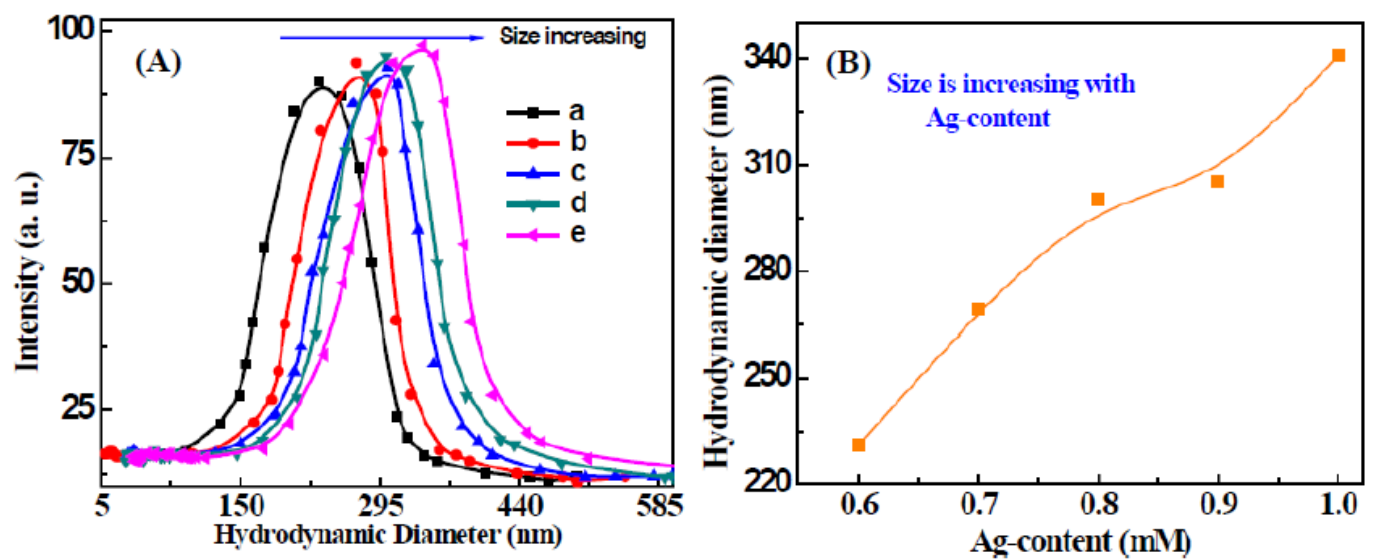

Figure 3. (A) Size distribution of liquid samples consisting of (a) 0.0, (b) 0.6, (c) 0.7, (d) 0.8, (e) 0.9, and (f) 1.0 $\mathrm{mM}$ Ag NPs in an aqueous raw fruit extract of Mimusops elengi and (B) variation of NPs size with Ag-content. 
From Figure $3 \mathrm{~B}$, it is found that the diameter of the Ag cluster is increasing with increasing the Ag content. This is due to the reason that as the Ag content increases in the sample, the relative number of phytochemical molecules per NPs decreases. As a result, the capping efficiency decreases due to a relative decrease in the number of capping molecules, and this causes an increase in clusters size of Ag. Jyoti et al. [16] have reported average size of $36 \mathrm{~nm}$ for synthesized Ag NPs, and they are polydisperse in nature. In another article size of $100 \mathrm{~nm}$ was reported for Ag NPs [20].

We also studied the distribution of zeta-potential around the surface of NPs to have an idea about the colloidal stability of Ag nano-colloids. Figure 4A. Shows the zeta-potential distribution of different samples consisting of (a) 0.0, (b) 0.6, (c) 0.7, (d) 0.8, (e) 0.9, and (f) 1.0 mM Ag NPs in an aqueous raw fruit extract of Mimusops elengi. We obtained negative zeta-potential for all our Ag nanofluids. This shows that Ag NPs are surrounded by the negative charge. We got the highest zeta-potential of (-) $25.8 \mathrm{mV}$ for a sample containing $0.6 \mathrm{mM} \mathrm{Ag}$ NPs and the lowest value for the sample containing $1.0 \mathrm{mM} \mathrm{Ag} \mathrm{NPs}$. This clearly suggests that as sample-a has the highest zeta-potential owing to their smallest size. We found from Figure 4B that with an increase in Ag-content or increase in size, the zeta-potential value decreases. In a report, a zeta-potential of $-25.1 \mathrm{mV}$ was reported for Ag-NPs [22]. Buszewski et al. [20] have reported an average zeta-potential value of $-32 \mathrm{mV}$ for $\mathrm{Ag}$ nanocolloids. Khorrami et al. [21] have reported zeta-potential value of $-33.7 \mathrm{mV}$ at $\mathrm{pH}=6.5$ at $25{ }^{0} \mathrm{C}$. They suggested that such a large value of zeta-potential causes the formation of highly stable nanocolloid particles in a liquid medium [20-22].

\subsection{XRD and Microstructural analysis using SEM.}

The crystalline nature of Ag NPs was studied using the XRD pattern. The XRD pattern of a sample consisting of $0.9 \mathrm{mM}$ Ag NPs was shown in Figure 4.

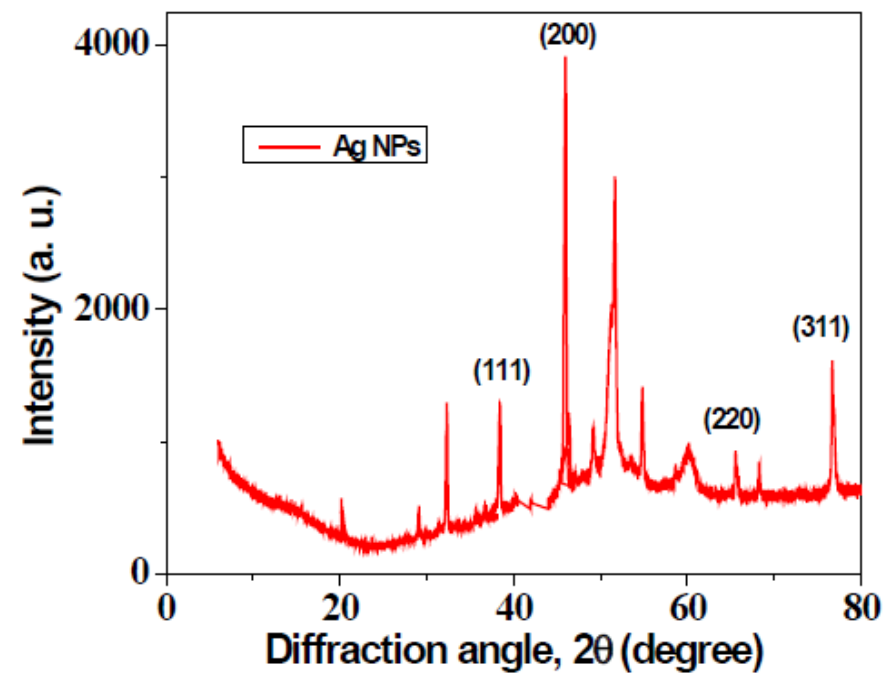

Figure 4. XRD patterns of a sample containing 0.9 mM Ag NPs with plant extract.

The characteristic diffraction peaks were observed at $38.45^{\circ}, 46.35^{0}, 64.75^{\circ}$, and $78.1^{0}$ in the $2 \theta$ range $10-80^{\circ}$, which can be indexed to the (111), (200), (220), and (311) planes of face-centered cubic (fcc) Ag-crystal, respectively [9,16-19]. The indexed planes have a good match with the standard diffraction pattern of JCPDS No. 01-087-0597 [9,16]. It discloses that the synthesized Ag NPs are composed of pure crystalline silver. The lattice type is of fcc. From 
the XRD-pattern, the intense peak corresponding to (200) plane. The XRD pattern suggests that the main orientation for NPs lies in the (200) plane.

The morphology, size details, and size distribution of the Ag NPs were studied using SEM images. Figure 5 depicts SEM images of Ag-NPs containing (A) 0.6 and (B) $1.0 \mathrm{mMAg}$ NPs with plant extract. From Figure 5A, it is found that the particles were of nearly spherical in shape, and their average diameter lies between 200-250 nm. The Ag NPs were encapsulated by phytochemicals. The size distribution is almost uniform. The diameter has increased to 300 $\mathrm{nm}$ in a sample containing $1.0 \mathrm{mM} \mathrm{Ag} \mathrm{NPs} \mathrm{(Figure} \mathrm{5B).} \mathrm{The} \mathrm{particles} \mathrm{were} \mathrm{found} \mathrm{to} \mathrm{be}$ interconnected via phytochemicals present in the plant extract.

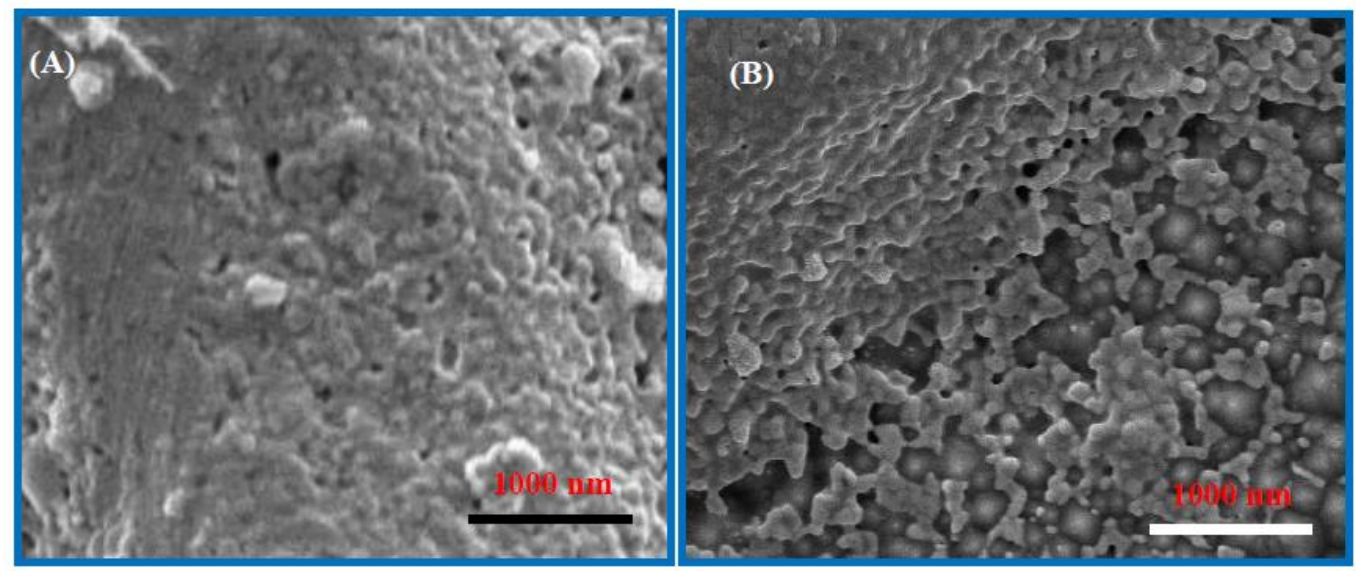

Figure 5. SEM image of Ag-NPs containing (A) 0.6 and (B) 1.0 mMAg NPs with plant extract.

\subsection{Analysis of the antibacterial activity of Ag NPs with plant extract.}

Two different pathogenic bacterial strains were used to study the antibacterial effect of prepared samples. One strain was gram-positive bacteria (i.e., Staphylococcus aureus), and another was gram-negative bacteria (i.e., Escherichia coli). We used the agar well diffusion method to study the antibacterial effect of phyto-synthesized Ag NPs. In order to study the antibacterial effect, wells were made using a sterile cork borer $(6 \mathrm{~mm})$ under aseptic conditions. The inocula were prepared by diluting the Ag NPs solution (aqueous Ag NPs) with $0.9 \% \mathrm{NaCl}$ to a $0.5 \mathrm{McF}$ arland standard and were swabbed onto the plates which were previously seeded by one of the tested pathogenic bacteria.

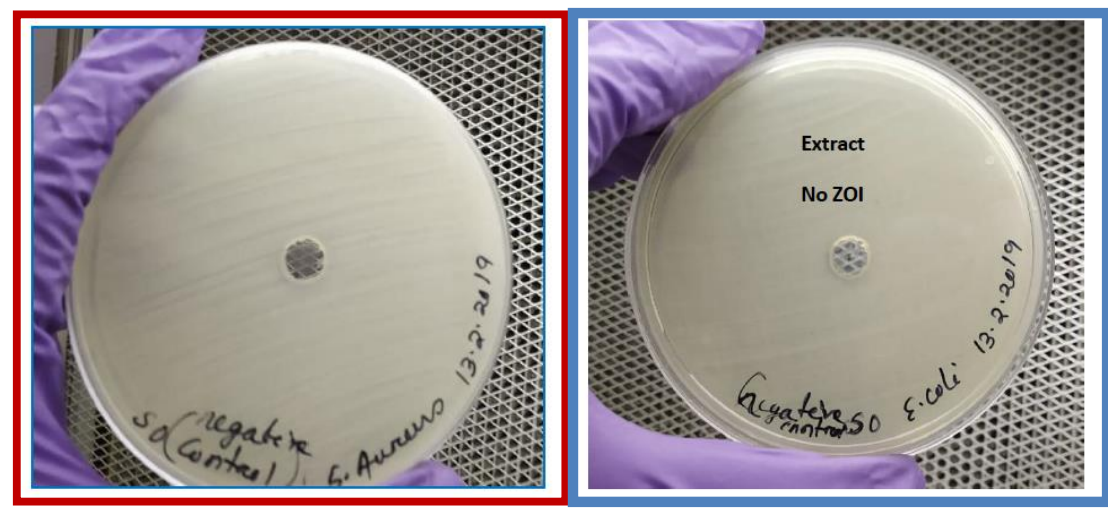

Figure 6. Antibacterial activity test of extract solution against (A) E. coli and (B) S. aureus.

Different concentrations of the Au NPs were loaded on marked wells with the help of micropipette under aseptic conditions, and plates were incubated at $37^{\circ} \mathrm{C}$, and incubation time was $\sim 24 \mathrm{~h}$. Then the diameter of the zone of inhibition (ZOI) was measured using a ruler and 
expressed in mm. Figure 6 shows the Antibacterial activity test of extract solution against $E$. coli and $S$. aureus. From the image, it is found that there is no antibacterial activity (no ZOI) of plant extract against $E$. coil. Figure 7 shows the antibacterial activity of Ag NPs of various concentrations: (S1) 0.6, (S2) 0.7, (S3) 0.8, (S4) 0.9, and (S5) 1.0 mM Ag NPs in an aqueous raw fruit extract of Mimusops elengi. against E. coli. The ZOI for samples (S1-S5) was calculated to be $15 \mathrm{~mm}, 16 \mathrm{~mm}, 17 \mathrm{~mm}, 14 \mathrm{~mm}$, and $14.5 \mathrm{~mm}$, respectively. So, maximum ZOI was found for the sample-S3 consisting of $0.8 \mathrm{mM}$ Ag NPs against these gram-negative bacteria.

Kiran Kumar et al. [9] have reported that their synthesized Ag NPs were showed higher activity towards $S$. aureus as compared to E. coli. The antibacterial activity against grampositive (Bacillus cereus, Bacillus subtilis, Staphylococcus aureus, and Staphylococcus epidermidis) and gram-negative (Escherichia coli, Klebsiella pneumoniae, Serratia marcescens and Salmonella typhimurium) bacterial pathogens were demonstrated by Jyoti et al. [16] using Ag NPs. They further studied the synergistic effects of Ag NPs with various antibiotics against all bacterial pathogens. Their results showed that Ag NPs, in combination with antibiotics, have a better antibacterial effect as compared with Ag NPs alone. So, they suggested that their samples can be used in the treatment of infectious diseases caused by bacteria.

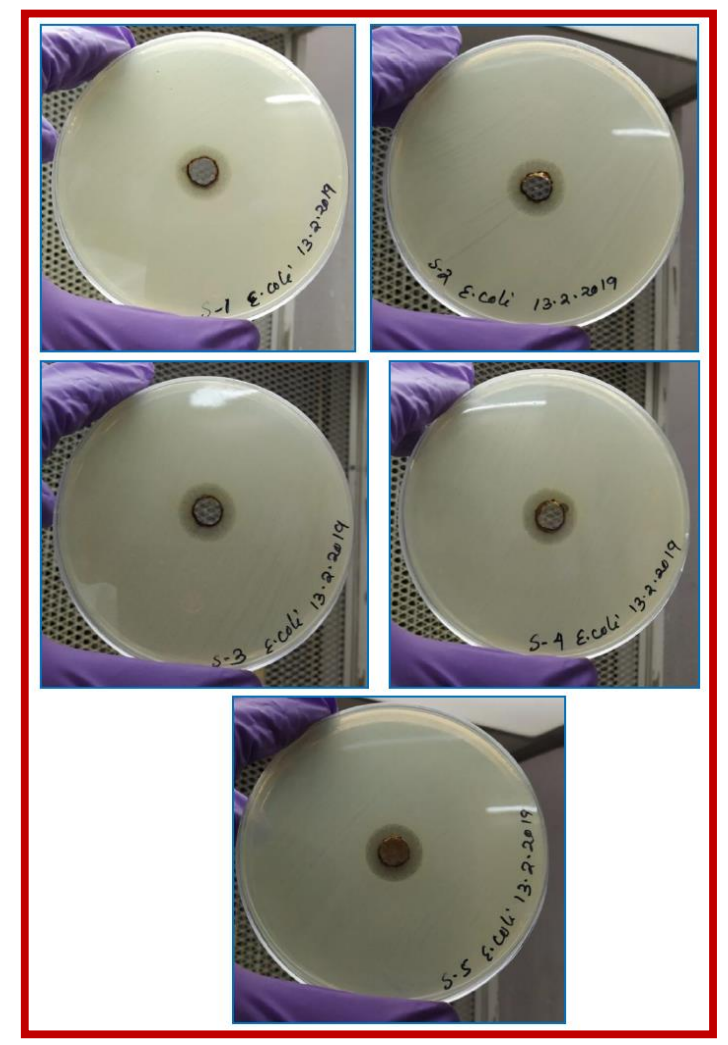

Figure 7. Antibacterial activity of Ag NPs of various concentrations: (S1) 0.6, (S2) 0.7, (S3) 0.8, (S4) 0.9, and (S5) $1.0 \mathrm{mM}$ Ag NPs in an aqueous raw fruit extract of Mimusops elengi. against E. Coli.

The maximum effect, with a 17.8 fold increase in inhibition zone, was reported for amoxicillin with Ag NPs against S. marcescens proving the synergistic role of Ag NPs. Prakash et al. [19] have synthesized Ag NPs using aqueous leaf extract of Mimusops elengi,v L. and studied antimicrobial efficacy against multi-drug-resistant clinical isolates. They reported that samples were showing a clear zone of inhibition against Klebsiella pneumonia, Micrococcus luteus, and Staphylococcus aureus. Ag-NPs synthesized using black peel pomegranate nanoparticles were able to kill the bacteria at a minimum bactericidal concentration of 40-65 
$\mu \mathrm{g} / \mathrm{ml}$ with minimum inhibitory concentration lies between $200-300 \mu \mathrm{g} / \mathrm{ml}$ [21]. In an article, Varadavenkatesan et al. [22] have reported that the Ag-Nps synthesized using aqueous flower extract of Ipomoea digitata Linn. exhibits good efficacy towards multi-drug resistant bacteria like Escherichia coli and Staphylococcus epidermidis. In another article, Kumar et al. [23] were reported the antimicrobial activity of the Ag NPs using a well diffusion method against four bacteria. These are Staphylococcus aureus, Pseudomonas aeruginosa, Escherichia coli, and Klebsiella pneumoniae. The highest antimicrobial activity of Ag NPs synthesized by $S$. tricobatum, O. tenuiflorum extracts were reported against $S$. aureus $(30 \mathrm{~mm})$ and E. coli (30 $\mathrm{mm}$ ), respectively. We also found that negative control has no antibacterial activity against the gram-positive bacteria $S$. aureus. (Figure 6B). Figure 8 shows the antibacterial activity of $\mathrm{Ag}$ NPs of various concentrations: (S1) 0.6, (S2)0.7, (S3) 0.8, (S4) 0.9, and (S5) $1.0 \mathrm{mM} \mathrm{Ag} \mathrm{NPs}$ in an aqueous raw fruit extract of Mimusops elengi. against $S$. aureus. The ZOI for samples (S1-S5) was calculated to be $14 \mathrm{~mm}, 12 \mathrm{~mm}, 19 \mathrm{~mm}, 11 \mathrm{~mm}$, and $12 \mathrm{~mm}$, respectively. So, the maximum ZOI found that it is against gram-positive bacteria for the sample-S3 consisting of $0.8 \mathrm{mM}$ Ag NPs.

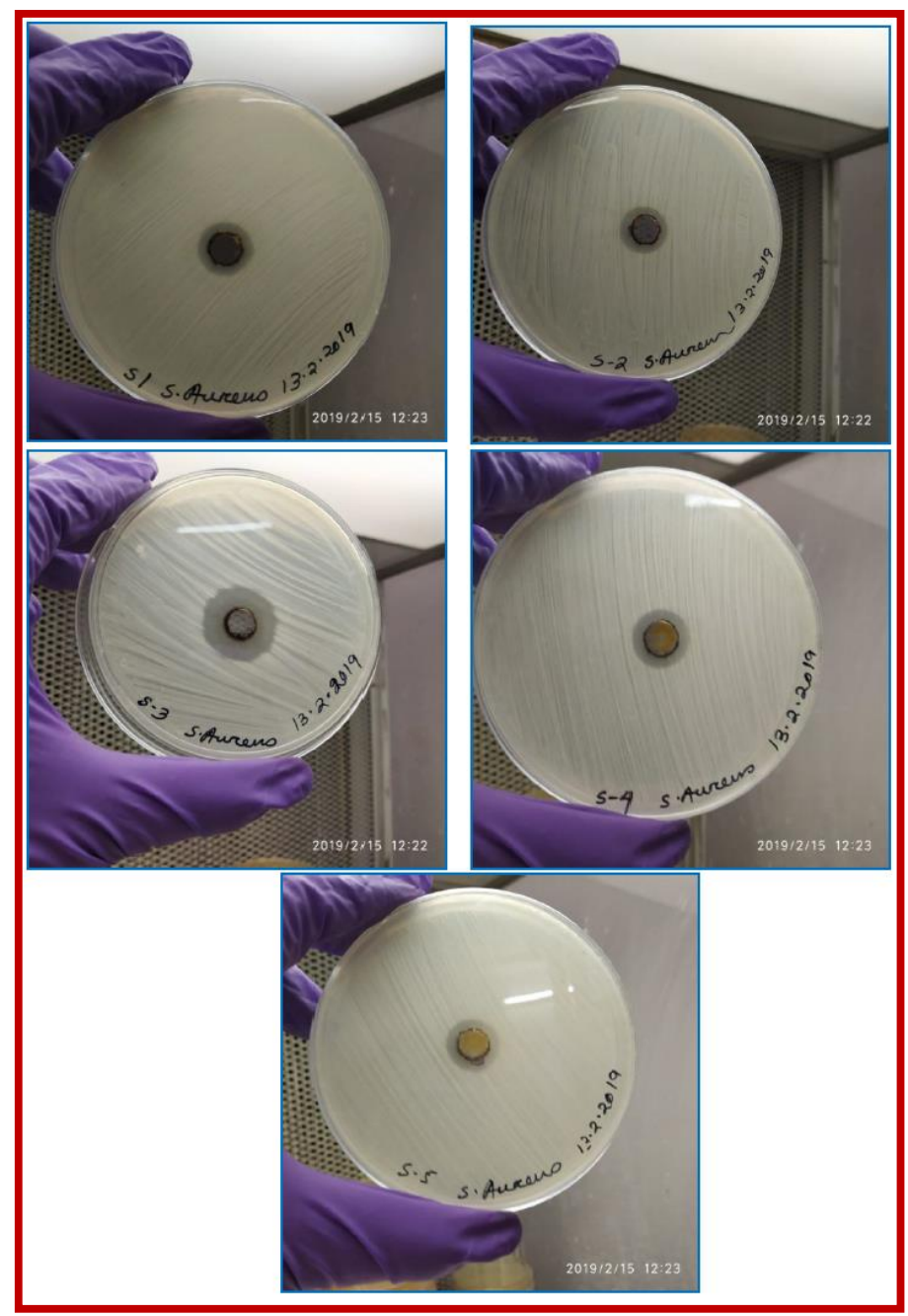

Figure 8. Antibacterial activity of Ag NPs of various concentrations: (S1) 0.6, (S2) 0.7, (S3) 0.8, (S4) 0.9, and (S5) $1.0 \mathrm{mM}$ Ag NPs in an aqueous raw fruit extract of Mimusops elengi. against $S$. aureus.

\subsection{Mechanism o formation of Ag NPs.}

It was reported that an aqueous extract of Mimusops elengi $L$. fruit is rich in many phytochemicals, which include polyphenols [24-26]. One such polyphenol is quercitol. These 
polyphenolic compounds contribute a lot to the synthesis NPs [22-25]. It is reported that quercetin molecules present in the Bakul Tree fruits play an important role in the bioreduction of metal ions like silver, copper, gold, etc. Approximately $3.63 \pm 0.07 \mathrm{mg}$ of quercetin equivalent/g of dry weight is present in the aqueous fruit extract of Mimusops elengi [27]. Quercetin is a strong ligand having three active sites. The susceptible sites like carbonyl $(\mathrm{C}=\mathrm{O})$ and hydroxyl (-OH) functional groups are not only helping in the reduction of $\mathrm{Ag}+-$ ions to $\mathrm{Ag}$ atoms but responsible for providing stability to Ag NPs in solution also. The electron-rich sites in quercetin molecules provide their electrons to electron-deficient Ag+-ions first to convert them to Ag-atoms and later Ag NPs via a bottom-up approach. After acting as a reducing agent, they sit on the surface of NPs to avoid agglomeration and hence acts as encapsulating agents. In support of experimental results, the probable scheme of forming Ag NPs is depicted in scheme 1B.

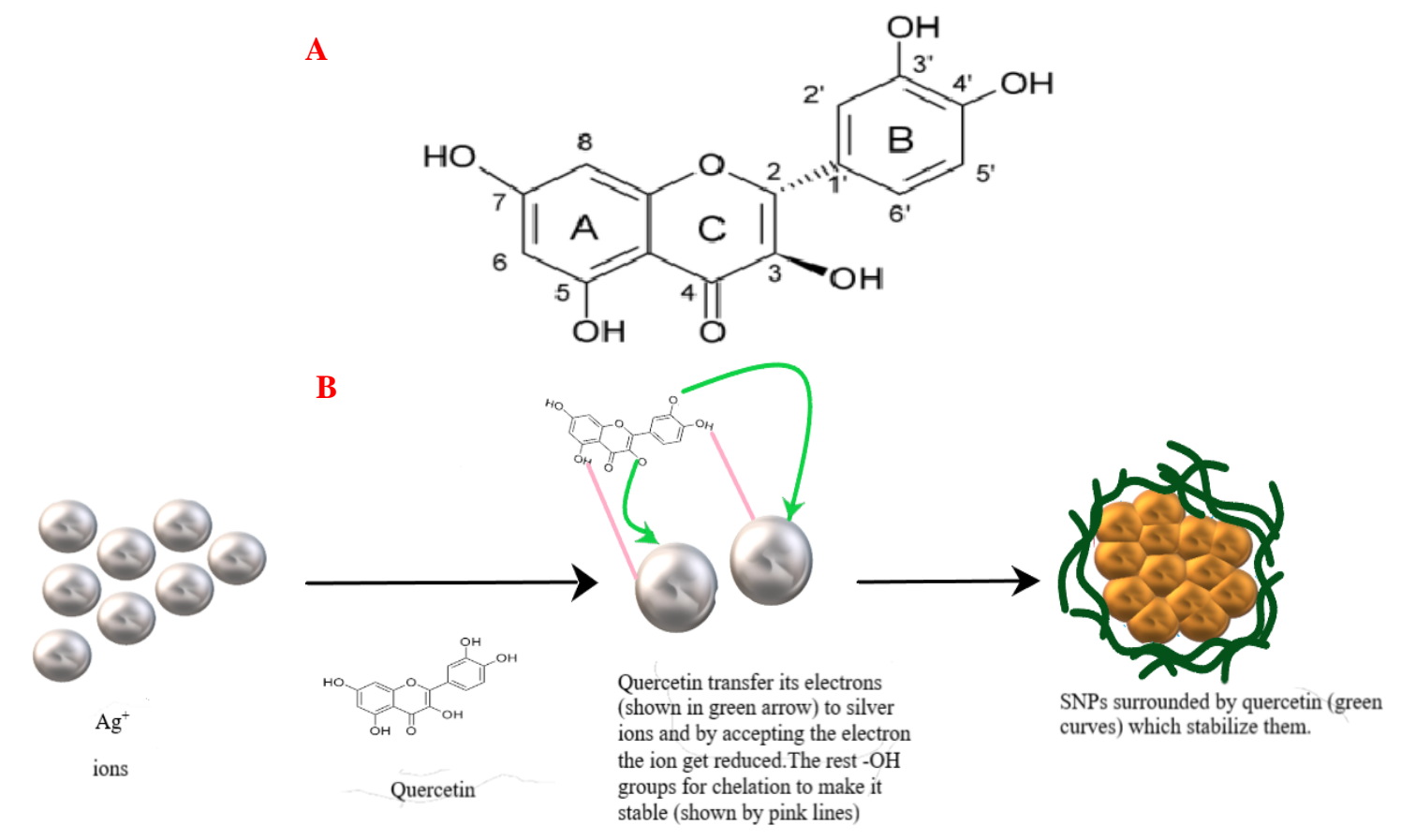

Scheme 1. (A) Structure of Quercetin, (B) Hypothetical mechanism of the synthesis of Ag NPs.

\section{Conclusions}

We have successfully developed Ag NPs using a fast, environmentally benign, and suitable method. We used an aqueous raw fruit extract of Mimusops elengi tree in synthesizing our series of $\mathrm{Ag}$ nanofluids. The extract has successfully reduced $\mathrm{Ag}$ (I) of $\mathrm{AgNO}_{3}$ salt to $\mathrm{Ag}$ (0). Cluster sizes of particles varied between 230-350 nm. The Ag NPs are polydisperse in nature and have a nearly spherical shape. The synthesized Ag NPs were characterized using UV-Vis, FTIR, XRD, DLS, SEM, and agar well diffusion method. UV-Vis spectral analysis and XRD analysis suggested that Ag NPs are formed from the precursor salt using plant extract. FTIR reveals that phytochemicals are not only acted as a reducing agent but also as a capping agent. XRD pattern confirms that Ag NPs are crystalline in nature. The antimicrobial sensitivity of the biosynthesized Ag NPs was evaluated against microbes, which include both bacteria and fungi. Samples have shown excellent antimicrobial activity against various pathogens. 


\title{
Funding
}

This research received no external funding.

\section{Acknowledgments}

\begin{abstract}
Support from Centurion University of Technology and Management, Odisha, India, and Silicon Institute of Technology, Bhubaneswar, India, is highly acknowledged.
\end{abstract}

\section{Conflicts of Interest}

On behalf of all authors, the corresponding authors (SKB and MB) states that there is no conflict of interest among the contributors.

\section{References}

1. Khan, I.; Saeed, K.; Khan, I. Nanoparticles: Properties, applications and toxicities. Arabian J Chem 2017, 12, 908-931, https://doi.org/10.1016/j.arabjc.2017.05.011.

2. Hashemi, S.F.; Tasharrofi, N.; Saber, M.M. Green synthesis of silver nanoparticles using Teucrium polium leaf extract and assessment of their antitumor effects against MNK45 human gastric cancer cell line. J Mol Str 2020, 1208, https://doi.org/10.1016/j.molstruc.2020.127889.

3. Kambale, E.K.; Nkanga, C.I.; Mutonkole, B.P.I.; Bapolisi, A.M.; Tassa, D.O.; Liesse, J.M.I.; Krause, R.W.; Memvanga, P.B. Green synthesis of antimicrobial silver nanoparticles using aqueous leaf extracts from three Congolese plant species (Brillantaisia patula, Crossopteryx febrifuga and Senna siamea). Heliyon 2020, 6 , https://doi.org/10.1016/j.heliyon.2020.e04493.

4. Alkhalaf, M.I.; Hussein, R.H.; Hamza, A. Green synthesis of silver nanoparticles by Nigella sativa extract alleviates diabetic neuropathy through anti-inflammatory and antioxidant effects. Saudi J Biol Sci 2020, 27, 2410-2419, https://doi.org/10.1016/j.sjbs.2020.05.005.

5. Khalil, M.M.H.; Ismail, E.H.; El-Baghdady, K.Z.; Mohamed, D. Green synthesis of silver nanoparticles using olive leaf extract and its antibacterial activity. Arabian J Chem 2013, 7, 1131-1139, http://dx.doi.org/10.1016/j.arabjc.2013.04.007.

6. Husseiny, S.M.; Salah, T.A.; Anter, H.A. Biosynthesis of size controlled silver nanoparticles by Fusarium oxysporum, their antibacterial and antitumor activities. Beni-Suef Univ J Basic Appl Sci 2015, 4,225-231, https://doi.org/10.1016/j.bjbas.2015.07.004.

7. Nakkala, J.R.; Mata, R.; Gupta, A.K.; Sadras, S.R. Biological activities of green silver nanoparticles synthesized with Acorous calamus rhizome extract. Eur J Med Chem 2014, 6, 784-94, https://doi.org/10.1016/j.ejmech.2014.08.024.

8. Jeyasundari, J.; Praba, P.S.; Jacob, Y. B.; Rajendran, S.; Kaleeswari, K. Green Synthesis and characterization of silver nanoparticles using Mimusops elengi flower extract and its synergistic antimicrobial potential. $\mathrm{Am}$ Chem Sci J 2016,12, 1-11,https://doi.org/10.9734/ACSJ/2016/23161.

9. Kumar, H.A.; Mandal, B.K.; Kumar, K.M.; Babu, M.S.; Kumar, T.S.; Madhiyazhagan, P.; Ghosh, A.R. Antimicrobial and antioxidant activities of Mimusops elengi seed extract mediated isotropic silver nanoparticles. Spectrochim ActaA Mol Biomol Spectrosc 2014, 130, 13-18, https://doi.org/10.1016/j.saa.2014.03.024.

10. Farjadian, F.; Akbarizadeh, A.R.; Tayebi, L. Synthesis of novel reducing agent for formation of metronidazole-capped silver nanoparticle and evaluating antibacterial efficiency in gram-positive and gramnegative bacteria. Heliyon 2020, 6, https://doi.org/10.1016/j.heliyon.2020.e04747.

11. Nilavukkarasi, M.; Vijayakumar, S.; Kumar, S.P. Biological synthesis and characterization of silver nanoparticles with Capparis zeylanica L. leaf extract for potent antimicrobial and anti proliferation efficiency. Mat Sci Energy Technol 2020, 3, 371-376, https://doi.org/10.1016/j.mset.2020.02.008.

12. Renuka R.; Devi K.R.; Sivakami M.; Thilagavathi T.; Uthrakumar R.; Kaviyarasu K. Biosynthesis of silver nanoparticles using phyllanthus emblica fruit extract for antimicrobial application. Biocatal Agric Biotechnol 2020, 7, 101567. https://doi.org/10.1016/j.bcab.2020.101567.

13. Hekmati, M.; Hasanirad, S.; Khaledi, A.; Esmaeili, D. Green synthesis of silver nanoparticles using extracts of Allium rotundum 1, Falcaria vulgaris Bernh, and Ferulago angulate Boiss, and their antimicrobialeffectsinvitro. Gen Reports 2020,19, https://doi.org/10.1016/j.genrep.2020.100589.

14. Sherin, L.; Sohail, A.; Mustafa, M.; Jabeen, R.; Ul-Hamid, A. Facile green synthesis of silver nanoparticles using Terminalia bellerica kernel extract for catalytic reduction of anthropogenic water pollutants. ColloidsInterface Sci.Commun. 2020, 37, https://doi.org/10.1016/j.colcom.2020.100276. 
15. Khan, T.; Yasmin, A.; Townley, H.E. An evaluation of the activity of biologically synthesized silver nanoparticles against bacteria, fungi and mammalian cell lines. Colloids Surf B Biointerfaces 2020, 194, https://doi.org/10.1016/j.colsurfb.2020.111156.

16. Jyoti, K.; Baunthiyal, M.; Singh, A. Characterization of silver nanoparticles synthesized using Urtica dioica Linn. leaves and their synergistic effects with antibiotics. J Radiat Res Appl Sci 2016,9, 217-227, https://doi.org/10.1016/j.jrras.2015.10.002.

17. Zaheer, Z. Silver nanoparticles to self-assembled films: green synthesis and characterization. Colloids Surf BBiointerfaces 2012, 90, 48-52, https://doi.org/10.1016/j.colsurfb.2011.09.037.

18. Bagherzade, G.; Tavakoli, M.M.; Namaei, M.H. Green synthesis of silver nanoparticles using aqueous extract of saffron (Crocus sativus L.) wastages and its antibacterial activity against six bacteria. Asian Pac J Trop Biomed 2017, 7 ,227-233, https://doi.org/10.1016/j.apjtb.2016.12.014.

19. Prakash, P.; Gnanaprakasam, P.; Emmanuel, R.; Arokiyaraj, S.; Saravanan, M. Green synthesis of silver nanoparticles from leaf extract of Mimusops elengi, Linn. for enhanced antibacterial activity against multi drug resistant clinical isolates.Colloids Surf BBiointerfaces 2013, 108, 255-259, https://doi.org/10.1016/j.colsurfb.2013.03.017.

20. Buszewski, B.; Railean-Plugaru, V.; Pomastowski, P.; Rafińska, K.; Szultka-Mlynska, M.; Golinska, P.; Wypij, M.; Laskowski, D.; Dahm, H. Antimicrobial activity of biosilver nanoparticles produced by a novel Streptacidiphilus durhamensis strain. $J$ Microbiol Immunol Infect 2018, 51, 45-54, https://doi.org/10.1016/j.jmii.2016.03.002.

21. Khorrami, S.; Kamali, F.; Zarrabi, A. Bacteriostatic activity of aquatic extract of black peel pomegranate and silver nanoparticles biosynthesized by using the extract. Biocatal Agric Biotechnol 2020,25, https://doi.org/10.1016/j.bcab.2020.101620.

22. Varadavenkatesan, T.; Selvaraj, R.; Vinayagam, R. Dye degradation and antibacterial activity of green synthesized silver nanoparticles using Ipomoea digitata Linn. flower extract. Int J Environ Sci Technol 2019, 16, 2395-2404, https://doi.org/10.1007/s13762-018-1850-4.

23. Kumar, R. S.; Malarkodi, C.; Paulkumar, K.; Vanaja, M.; Gnanajobitha, G.; Annadurai, G. Algae mediated green fabrication of silver nanoparticles and examination of its antifungal activity against clinical pathogen. Int J Met 2014, 2014, 8,https://doi.org/10.1155/2014/692643.

24. Rani, S.;Rahman, K. Molsari (Mimusops Elengi Linn.): A Boon Drug Of Traditional Medicine.International Journal Of Pharmaceutical Sciences And Research 2017, 8, 17-28, https://doi.org/10.13040/IJPSR.09758232.8(1).17-28.

25. Baliga, M.S.; Pai, R.J.; Bhat, H.P.; Palatty, P.L.; Boloor, R. Chemistry and medicinal properties of the Bakul (Mimusops elengi Linn): a review. Food Res Int2011, 44,1823-1829, http://dx.doi.org/10.1016/j.foodres.2011.01.063.

26. Gami, B.; Pathak, S.; Parabia, M. Ethnobotanical, phytochemical and pharmacological review of Mimusops elengi Linn. Asian Pac J Trop Biomed 2012, 2,743-748, https://doi.org/10.1016/S2221-1691(12)60221-4.

27. Mathur, R.;Vijayvergia, R. Determination Of Total Flavonoid And Phenol Content In Mimusops Elengi Linn. International Journal Of Pharmaceutical Sciences And Research 2019, 8, 5282-85, https://doi.org/10.13040/IJPSR.0975-8232.8(12).5282-85. 